\title{
IN VITRO ANTI-TUMOUR ACTIVITY OF TUMOUR NECROSIS SERUM
}

\author{
Nanne Bloksma,* Theo P. Schetters, Carl Figdor, Hans van DiJk and Jan M. Willers \\ Department of Immunology, Laboratory of Microbiology, State University of Utrecht, Catharÿnesingel 59, 3511GG \\ Utrecht, The Netherlands
}

(Received 30 October 1979 and in final form 18 December 1979)

* Dr. Bloksma is supported by a grant of the Stichting Koningin Wilhelmina Fonds, Nederlandse Organisatie voor de Kankerbestrijding.

\begin{abstract}
A method measuring ${ }^{3} \mathrm{H}$-thymidine incorporation in Meth A sarcoma cells was used to quantify in vitro anti-tumour activity of tumour necrosis serum and compared with a method using cell viability as a parameter. Tumour necrosis serum obtained from mice pretreated with Corynebacterium parvum and elicited with endotoxin two weeks later greatly inhibited ${ }^{3} \mathrm{H}$-thymidine incorporation, whereas sera of normal mice and of mice treated with $C$. parvum or endotoxin alone were much less inhibitory. All sera reduced viable cell numbers, tumour necrosis serum being most active.

The ${ }^{3} \mathrm{H}$-thymidine incorporation assay is suited for screening mouse sera on anti-tumour activity. It was shown that the anti-tumour activity of normal mouse serum can be potentiated by in vivo pretreatment of mice with bacterial agents. The mechanism of the anti-tumour action(s) and the factor(s) involved remain to be elucidated.
\end{abstract}

The induction of haemorrhagic necrosis of tumours is a well known effect of lipopolysaccharides (Gratia \& Linz, 1931; Shear, 1944; Nowotny, 1969; Parr, Wheeler \& Alexander, 1973). This phenomenon is not only provoked by lipopolysaccharide (LPS) itself but also by serum of LPS-treated mice (O'Malley, Achinstein \& Shear, 1962) and to an even greater extent by sera of mice stimulated with Bacille Calmette-Guérin (BCG), Corynebacterium parvum (Cp), C. granulosum, or zymosan and elicited with LPS. The activity of these sera (generally referred to as tumour necrosis sera or TNS), was attributed to an induced serum factor designated tumour necrosis factor (TNF) and not to residual LPS (Carswell, Old, Kassel, Green, Fiore \& Williamson, 1975). Although TNS causes both haemorrhagic necrosis and regression of Meth A sarcoma in vivo, it was only moderately cytotoxic for these cells in vitro, as determined by trypan blue dye exclusion (Carswell et al., 1975). The serum was, however, very cytotoxic for mouse L-929 cells but not for BALB/c embryo fibroblasts, suggesting specificity for tumour cells. Growth inhibition experiments revealed that TNS was more cytostatic than cytotoxic for Meth A cells in vitro.

The lack of correlation between in vivo and in vitro activity of TNS against Meth A sarcoma cells prompted a search for an in vitro method, which would be more sensitive and less laborious than the hitherto used method and also more suitable for large-scaled screening. Here we describe the develop- ment of a micro-method based on the inhibition of ${ }^{3} \mathrm{H}$-thymidine incorporation in Meth A cells. This method is compared with the cytotoxicity test of Carswell et al. (1975), modified for microculture plates.

\section{EXPERIMENTAL PROCEDURES}

\section{Preparation of the sera}

Sera were prepared as described by Green, Dobrjansky, Chiasson, Carswell, Schwartz \& Old (1977) in female Swiss random mice obtained from the Central Institute for the Breeding of Laboratory Animals (CPB, Zeist, The Netherlands). TNS was designated according to the inducing and eliciting agents. For the preparation of TNS (Cp/LPS) 14-week-old animals were injected intravenously (i.v.) with $1 \mathrm{mg}$ Cp (Coparvax, lot CA 582B, kindly provided by Wellcome Nederland B.V.) suspended in $0.5 \mathrm{ml}$ saline. Two weeks later the mice were injected i.v. with $25 \mu \mathrm{g}$ LPS w from E. coli 0111:B4 (Difco Laboratories, Detroit, Michigan, U.S.A.) in $0.5 \mathrm{ml}$ saline. The animals were exsanguinated by retroorbital puncture $90 \mathrm{~min}$ after the LPS injection. Control sera obtained after injection of mice with only a $\mathrm{Cp}$ suspension or a LPS solution or saline are referred to as $\mathrm{Cp} /-$ serum, -/LPS serum and normal mouse serum (NMS). The sera were stored in a lyophilized form or for short periods, small aliquots 
were frozen $\left(-70^{\circ} \mathrm{C}\right)$. The sera were tested on the induction of haemorrhagic necrosis of subcutaneously growing Meth A tumours in BALB/c mice. Only TNS(Cp/LPS) was positive in this test and was used for further experiments.

\section{Meth A sarcoma}

The Meth A sarcoma was kindly supplied by Dr. C. M. Hetherington, Clinical Research Centre, Harrow, Middlesex, U.K.) and maintained in ascitic form by serial intraperitoneal (i.p.) passage in $\mathrm{BALB} / \mathrm{c}$ mice. Tumour cells from approximately 6-days-old tumour transplants were collected in Eagle's minimal essential medium containing $100 \mathrm{U}$ penicillin $/ \mathrm{ml}, 100 \mu \mathrm{g}$ streptomycin $/ \mathrm{ml}, 2 \mathrm{mg}$ $\mathrm{NaHCO}_{3} / \mathrm{ml}$ and non-essential amino acids (Flow Laboratories, Irvine, Scotland, U.K.), further referred to as medium. The cells were washed at least thrice in medium by low gravity centrifugation until virtually free of erythrocytes and then resuspended in medium supplemented with $12.5 \%$ heat-inactivated $\left(30 \mathrm{~min}\right.$ at $56^{\circ} \mathrm{C}$ ) fetal calf serum (FCS; Flow Laboratories). Viable cells were diluted to the desired concentration after counting by trypan blue exclusion. In preliminary experiments the addition of $12.5 \% \mathrm{FCS}$, which results in a final experimental concentration of $5 \%$, appeared to be optimal for cell survival and for discriminating between TNS (Cp/LPS) and NMS activity. FCS containing medium will hereafter be called FCS medium.

\section{In vitro tumour assays}

To round-bottomed wells $(300 \mu \mathrm{l})$ of tissue culture plates (Greiner, Nürtingen, Germany) were added $100 \mu \mathrm{l}$ of mouse serum diluted in medium and $100 \mu \mathrm{l}$ of a freshly isolated Meth A tumour cell suspension. The concentrations of the mouse sera have been expressed as the dilution in percent $(\mathrm{v} / \mathrm{v})$ after addition of thymidine to the well (final volume in the well, 250 $\mu$ l). The plates were incubated for different periods at $37^{\circ} \mathrm{C}$ in an atmosphere of $5 \% \mathrm{CO}_{2}$ in saturated humidified air. Sixteen hours before termination of the incubation, each well was supplied with $50 \mu 1$ medium containing $1 \mu \mathrm{Ci}$ methyl- ${ }^{3} \mathrm{H}$ thymidine (specific activity $5 \mathrm{Ci} / \mathrm{mmol}$, Radiochemical Centre, Amersham, U.K.) or with a corresponding amount of unlabelled thymidine. After the incubation period the cells in the plates incubated with labelled thymidine were harvested using a multiple sample harvester (Skatron, Lierbyen, Norway), washed with water and collected on glass fibre filters. The filters were dried and transferred to scintillation vials. After addition of a toluene based scintillation fluid incorporated radioactivity, expressed as disintegrations per minute (DPM), was measured in a Mark
II liquid scintillation counter (Nuclear Chicago, Chicago, Illinois, U.S.A.). The plates with unlabelled thymidine were used for the determination of viable tumour cells by trypan blue dye exclusion.

Both viability and ${ }^{3} \mathrm{H}$-thymidine incorporation were tested in quadruplicate cultures.

\section{Data handling and statistical analysis}

Cytostatic indices $(\mathrm{Cl})$ were calculated by the formula:

$\mathrm{CI}=\frac{\mathrm{DPM}_{\mathrm{FCS} \text {-medium }}-\mathrm{DPM}_{\mathrm{FCS}-\text { medium with mouse serum }}}{\mathrm{DPM}_{\mathrm{FCS} \text {-medium }}}$.

Viability indices (VI) were determined by the formula:

number of viable cells in FCS-medium with

$\mathrm{VI}=\frac{\text { mouse serum }}{\text { number of viable cells in FCS-medium }}$.

Results have been expressed as the arithmetic mean of the numbers of viable cells or the mean of $\log _{10}$ (disintegrations per minute) per well \pm the standard error of the mean (S.E.M.). Significancy analysis was done with the use of Student's $t$-test and by determination of the coefficient of correlation with the method of least squares. $P$-values exceeding 0.05 were not considered to be significant.

\section{RESULTS}

Effects of mouse serum concentration on the ${ }^{3} \mathrm{H}-$ thymidine incorporation by Meth A cells

Meth A cells $\left(10^{5}\right)$ were incubated in the presence of graded concentrations of NMS or TNS (Cp/LPS) for $40 \mathrm{~h}$ and the ${ }^{3} \mathrm{H}$-thymidine incorporation was measured. The results summarized in Fig. 1 indicate that both NMS and TNS(Cp/LPS) gave slight inhibition of ${ }^{3} \mathrm{H}$-thymidine incorporation in concentrations up to $1 \%$, when compared with FCS-medium only. At higher concentrations the effects of TNS $(\mathrm{Cp} / \mathrm{LPS})$ and NMS increased and diverged. The greatest effect of TNS(Cp/LPS) was observed at the highest concentration tested $(20 \%)$ and differed considerably from that of NMS. The latter serum concentration was used in further experiments.

\section{Effect of cell numbers on the inhibition of ${ }^{3} \mathrm{H}$-thymi- dine incorporation}

Increasing cell numbers were added per well and incubated in the absence or presence of $20 \%$ TNS (Cp/LPS) or NMS. In the absence of mouse serum the ${ }^{3} \mathrm{H}$-thymidine incorporation was almost directly proportional to the cell number (Fig. 2). A similar effect was observed for NMS but the curve was less 
steep, so that NMS at cell numbers below $2.5 \times 10^{4}$ was stimulatory and only inhibitory at greater cell concentration. The curve for TNS(Cp/LPS) had a typical biphasic form, initially rising until cell numbers of $2.5 \times 10^{4}$ were reached and declining thereafter. For all cell numbers, tested TNS (Cp/LPS) was inhibitory compared to NMS. With medium the inhibitory effect of TNS(Cp/LPS) was nil at a cell concentration of $3 \times 10^{3}$ but thereafter increased with the cell number. In further experiments the cell number of $10^{5}$ was used.

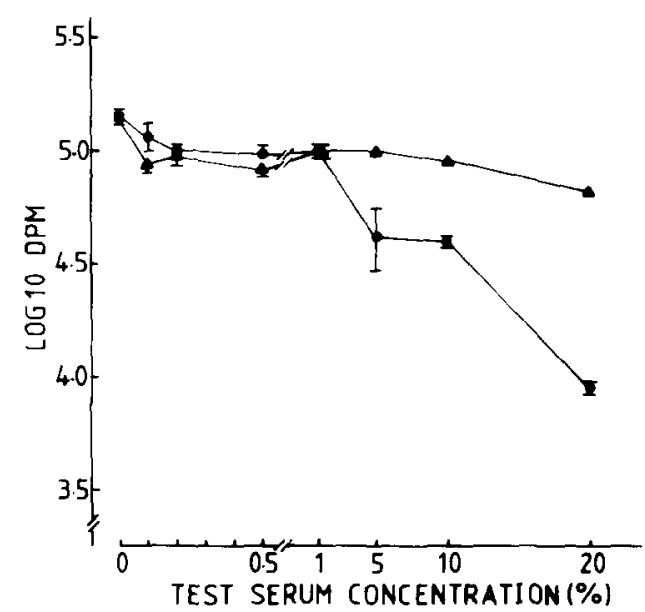

Fig. 1. Concentration effect of NMS ( $\Lambda$ ) and TNS(Cp/ LPS) ( $\bullet$ ) on the ${ }^{3} \mathrm{H}$-thymidine incorporation of $10^{5} \mathrm{Meth}$ A sarcoma cells after $40 \mathrm{~h}$ incubation. Vertical bars indicate S.E.M.

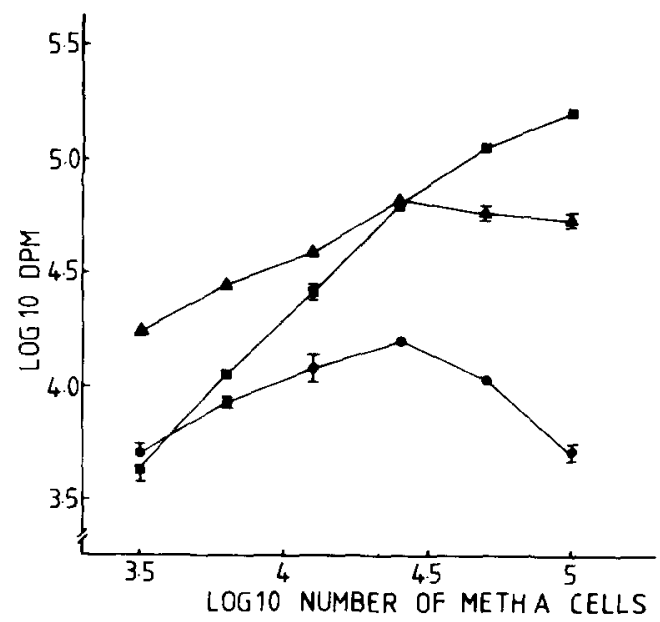

Fig. 2. Effect of varying the Meth A cell numbers on the ${ }^{3} \mathrm{H}$-thymidine incorporation in the absence $(\square)$ or presence of $20 \%$ NMS ( 4 ) and TNS(Cp/LPS) (e). The incubation time was 40 h. Vertical bars indicate S.E.M.
Influence of the incubation time on the ${ }^{3} \mathrm{H}$-thymidine incorporation and cell viability

Meth A sarcoma cells ( $10^{5}$ cells/well $)$ were cultured in FCS-medium or exposed to $20 \%$ TNS(Cp/LPS), $\mathrm{Cp} /-$ serum, -/LPS serum, or NMS for varying periods. With time an overall decrease in ${ }^{3} \mathrm{H}$-thymidine incorporation was observed for each serum tested (Fig. 3a). The curve for FCS-medium showed an optimum at $24 \mathrm{~h}$. All sera were inhibitory throughout compared to FCS-medium alone. The
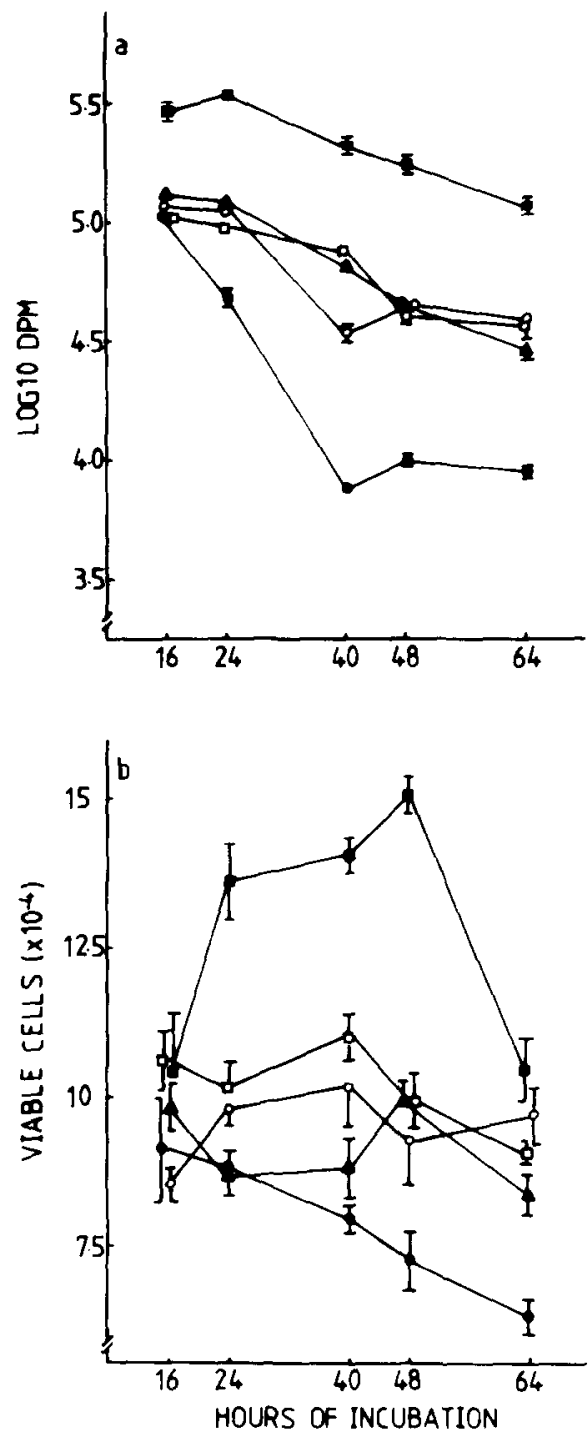

Fig. 3. Effect of incubation time on ${ }^{3} \mathrm{H}$-thymidine incorporation (a) and on the numbers of viable Meth A cells (b). Cultures of $10^{5}$ Meth A cells were incubated in FCSmedium (D), FCS-medium with 20\% NMS (A), Cp/-serum $(\bigcirc),-/$ LPS serum $(\square)$, or TNS (Cp/LPS) (•). Vertical bars indicate S.E.M. 


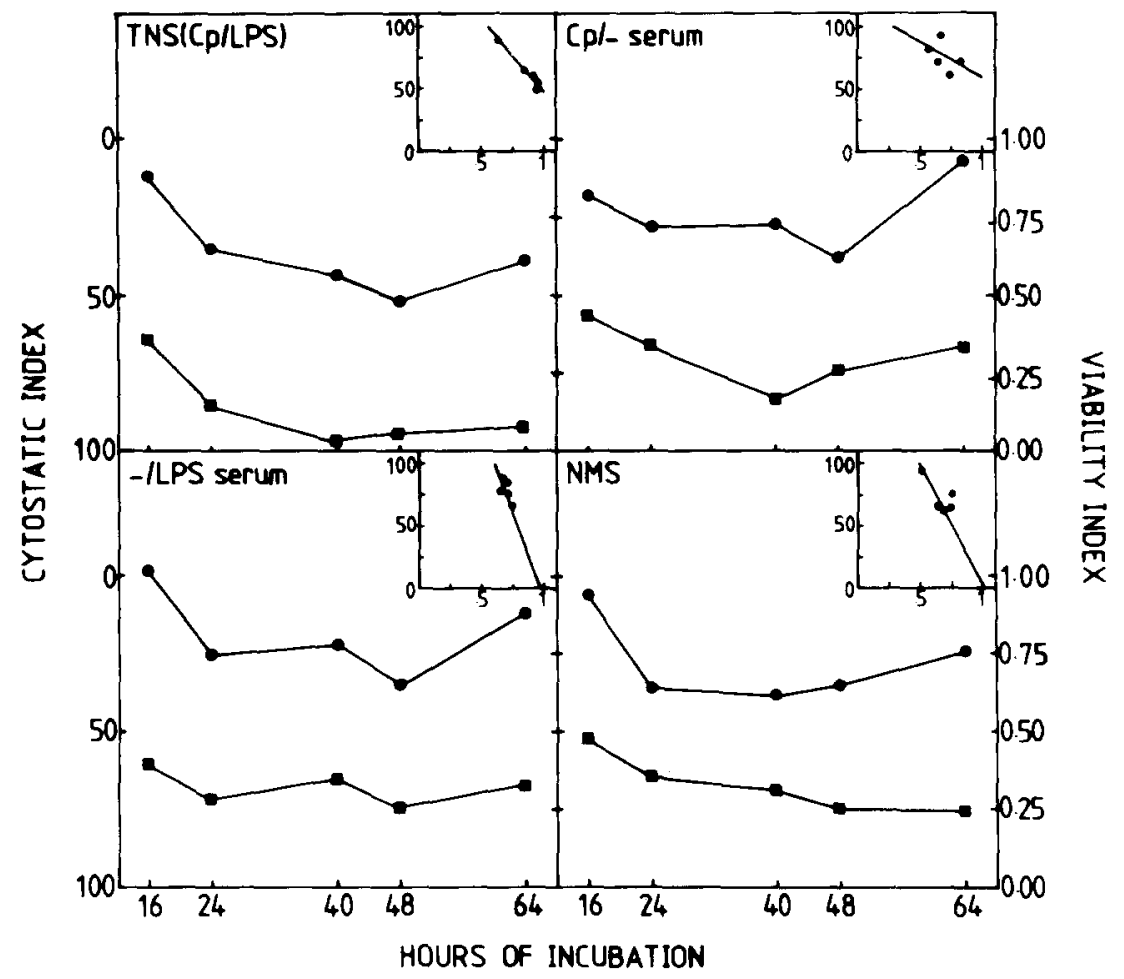

Fig. 4. Cytostatic $(\bullet)$ and viability $(\boldsymbol{\square})$ indices and their correlation. (inserts) Cultures of $10^{5}$ Meth A cells were incubated for various periods in FCS-medium as such or supplemented with $20 \%$ TNS(Cp/LPS), Cp/-, or -/LPS serum, or NMS. The correlation between the two indices was significant for cultures with TNS(Cp/LPS) $(P<0.01)$ and with -/LPS serum $(P<0.025)$.

effects of $\mathrm{Cp} /$ - and -/LPS sera did not considerably deviate from that of NMS. After $24 \mathrm{~h}$ or more of incubation the inhibitory activity of TNS(Cp/LPS), however, was greater than that of the three control sera, reaching a maximum at $40 \mathrm{~h}$. The number of viable cells in FCS-medium increased with the incubation time to reach a peak at $48 \mathrm{~h}$ (Fig. 3b). In the presence of control sera the cell numbers remained about constant, whereas in TNS(Cp/LPS) the numbers of viable cells diminished in a timedependent way. Unfortunately, the fast disintegration of dead cells made it impossible to determine the sum of living and dead cells.

The results of Fig. 3 for the different sera were expressed as cytostatic and viability indices (Fig. 4) and plotted against time and each other (Fig. 4, inset). Only for TNS(Cp/LPS) and -/LPS serum were the cytostatic indices significantly correlated with the viability indices.

\section{DISCUSSION}

The method for measuring anti-Meth $A$ cell activity in vitro we described is based on the inhibition by TNS of ${ }^{3} \mathrm{H}$-thymidine incorporation in Meth
A cells and was performed on a microscale. Optimal conditions for our test system included the presence of $5 \%$ FCS, $20 \%$ test serum, and $10^{5}$ tumour cells per final volume of $250 \mu \mathrm{l}$ and an incubation time of 40 $\mathrm{h}$. The test sera used were representative as judged by their in vivo activity.

Concentrations of TNS beyond $1 \%$ were dosedependently inhibitory for DNA synthesis in Meth A cells, as measured by the ${ }^{3} \mathrm{H}$-thymidine incorporation assay (Fig. 1). The background activity of NMS can partly be ascribed to the presence of minor amounts of TNF (Shah, Green \& Moore, 1978; Green, Chiasson \& Shah, 1979) and partly to another factor shown to inhibit DNA synthesis by mouse lymphocytes (Nelson \& Shneider, 1974; Smith \& Hammarström, 1979). This factor shares some physicochemical characteristics with TNF such as its nondialysable glycoprotein nature, its heat-stability ( 30 $\min , 56^{\circ} \mathrm{C}$ ) and its electrophoretic mobility as an a-globulin (Nelson \& Shneider, 1974; Green, Dobrjansky, Carswell, Kassel, Old, Fiore \& Schwartz, 1976). TNF, however, has another elution pattern on Sephadex $G_{200}$ (Green et al., 1976) and unlike the other inhibitory factor (Nelson, 1972), cannot be 
demonstrated nor induced in serum of nude mice (Hoffmann, Oettgen, Old, Mittler \& Hammerling, 1978).

Cell density also influenced the results of the test (Fig. 2). The typical biphasic course of the curve for TNS and to a lesser degree, the curve for NMS, might indicate the involvement of a mediator cell in the in vitro action of TNS. The possible mediator cell could well be a macrophage, which is certainly present in the peritoneal exudate of the ascitic Meth A sarcoma. The disproportional course of the curve for NMS as compared with the almost linear curve for FCS-medium and the curve for TNS suggests the presence of an easily exhaustible stabilizing factor in NMS which is obviously absent in TNS. At high cell concentrations, however, this factor did not appear to influence the results.

In producing and explaining the time-response curves we were faced with several problems, especially the rapid disintegration of dead cells which complicated the study of the relationship between ${ }^{3} \mathrm{H}$-thymidine incorporation and cytotoxicity. Similar problems were met by Ostrove \& Gifford (1979) in estimating dead L-929 cells after incubation with rabbit TNS. Cell disintegration may possibly result in reutilization of thymidine, thus explaining the discrepancy between decreasing DNA synthesis and increasing viable cell numbers in the absence of test (mouse) sera (Fig. 3). A second indication for cell turnover is the almost constant number of viable cells in the presence of control sera despite a rather high ${ }^{3} \mathrm{H}$-thymidine incorporation. The lag time observed for the effect of TNS in both systems, is in agreement with the findings of other workers who studied the effects of mouse and rabbit TNS on L-929 cells (Carswell et al., 1975; Ostrove \& Gifford, 1979) and suggests that TNS is not directly cytotoxic but rather acts on dividing cells. This conclusion seems to be supported by the delay in TNS effects on the number of viable cells as compared with the inhibition of DNA synthesis. The effectiveness of TNS in inhibiting DNA synthesis by Meth A cells makes the ${ }^{3} \mathrm{H}$-thymidine incorporation assay preferable to the cell viability test. The observation that the activities of the three control sera were similar in either system agrees with the findings of Carswell et al. (1975). Occasionally we observed enhanced activity in sera from LPStreated mice. As macrophage activation seems to be a prerequisite for the induction of TNF, it is conceivable that in such cases the macrophages of the donor mice were activated as a consequence of a latent infection or inflammation.

In conclusion, the inhibition of ${ }^{3} \mathrm{H}$-thymidine incorporation is a more sensitive tool for measuring the in vitro activity of TNS against Meth A cells compared to cell viability determinations by trypan blue exclusion. The assay as described here should be suitable for large-scale screening for agents that can potentiate the anti-tumour activity of various sera. Comparative studies of the in vitro and in vivo activity of more purified fractions of TNS against Meth A must be carried out to ascertain whether or not TNF is the common active agent or if different factors are involved.

Acknowledgements-The authors are indebted to Miss Petra Schmiermann and Miss Pieternel Rademaker for their participation in the experiments.

\section{REFERENCES}

Carswell, E. A., Old, L. J., Kassel, R. L., Green, S., Fiore, N. \& Williamson, B. (1975). An endotoxin-induced serum factor that causes necrosis of tumors. Proc. natn. Acad. Sci. U.S.A., 72, 3666-3670.

Gratia, A. \& Linz, R. (1931). Le phénomène de Shwartzman dans le sarcome du Cobaye. C.r. Séanc. Soc. Biol. Ses. Fil., $108,427-428$.

Green, S., Dobrjansky, A., Carswell, E. A., Kassel, R. L., Old, L. J., Fiore, N. \& Schwartz, M. K. (1976). Partial purification of a serum factor that causes necrosis of tumors. Proc. natn. Acad. Sci. U.S.A., 73, $381-386$.

Green, S., Dobrjansky, A., Chiasson, M. A., Carswell, E., Schwartz, M. K. \& Old, L. J. (1977). Corynebacterium parvum as the priming agent in the production of tumor necrosis factor in the mouse. J. natn. Cancer Inst., 59, $1519-1522$.

Green, S., Chiasson, M. A. \& ShaH, R. G. (1979). Evidence for the presence of an antitumor factor in serum of normal animals. Cancer Lett., 6, 235-240.

Hoffmann, M. K., Oettgen, H. F., Old, L. J., Mittler, R. S. \& Hammerling, U. (1978). Induction and immunological properties of tumor necrosis factor. $J$, reticuloendoth. Soc., 23, 307-319.

Nelson, D. S. (1972). Mouse serum factor depressing lymphocyte transformation. Experientia, 28, $1227-1228$.

Nelson, D. S. \& Shneider, C. N. (1974). Effect of normal mouse serum on mouse lymphocyte transformation in vitro. Eur. J. Immun., 4, 79-86.

Nowotny, A. (1969). Molecular aspects of endotoxic reactions. Bact. Rev., 33, 72-98.

O'Malley, W. E., Achinstein, B. \& Shear, M. J. (1962). Action of bacterial polysaccharide on tumors. II. Damage of sarcoma 37 by serum of mice treated with Serratia marcescens polysaccharide and induced tolerance. J. natn. Cancer Inst., 29, 1169-1175. 
Ostrove, J. M. \& Gifford, G. E. (1979). Stimulation of RNA synthesis in L-929 cells by rabbit tumor necrosis factor. Proc. Soc. exp. Biol. Med., 160, 354-358.

PARR, I., Wheeler, E. \& Alexander, P. (1973). Similarities of the anti-tumour actions of endotoxin, lipid A and doublestranded RNA. Br. J. Cancer, 27, 370-389.

Shah, R. G., Green, S. \& Moore, M. A. S. (1978). Colony stimulating and inhibiting activities in mouse serum after Corynebacterium parvum-endotoxin treatment. J. reticuloendoth. Soc., 23, 29-41.

SHEAR, M. J. (1944). Chemical treatment of tumors. IX. Reactions of mice with primary subcutaneous tumors to injection of a hemorrhage-producing bacterial polysaccharide. J. natn. Cancer Inst., 4, 461-476.

SMith, C. I. E. \& HaMmARSTRÖM, L. (1979). Regulation of lymphocyte activation by serum factors. Int. Archs Allergy appl. Immun., 58, 219-226. 